\title{
Primary care problems in patients attending a semi-rural accident and emergency unit: a prospective study
}

\author{
R L Cottingham
}

\begin{abstract}
Objective-To analyse the characteristics of patients attending a coastal resort accident and emergency (A\&E) unit and compare use by summer visitors with use by the indigenous winter population by previously validated assessment criteria. Setting-Accident and emergency unit of a semi-rural coastal town district general hospital.

Subjects-3643 first attenders in the summer cohort and 2876 in the winter cohort. Methods-All patients attending the A\&E unit over two 28 day periods in summer and winter 1995 were assessed prospectively in four categories by trained, experienced nurse assessors. Category 4 identified patients who fulfilled the King's College Hospital criteria as being suitable for care from primary care practitioners. Results $-43.8 \%$ of the summer patients could have been seen in the primary care setting, as could $38.7 \%$ of the winter visitors.

Conclusions-The proportion of patients with primary care problems who attend semi-rural A\&E units appears to be much higher than previously thought. These findings cast doubt on the validity of the King's College Hospital criteria for classifying patients to either primary care or A\&E categories.

(F Accid Emerg Med 1998;15:168-169)
\end{abstract}

Keywords: semi-rural A\&E unit; holiday attendances; primary care problems

Patients attending accident and emergency (A\&E) units with problems that could readily be dealt with in primary care create problems for the providers and affect the overall quality of service. Waiting times are prolonged, staff can become resentful of a perceived misuse of the service, and managers become concerned that while resources are being channelled into primary care patients are using secondary care facilities. It is thought that such problems are worst in deprived wards of inner cities. A prospective study from King's College Hospital ${ }^{1}$ examined attendance patterns at their $A \& E$ unit. It showed that $40.9 \%$ of patients attending could have been dealt with by an "average local general practice." The study was the first to propose criteria defining what could reasonably be dealt with in such a setting and thus what may be termed inappropriate attendance at the $A \& E$ unit.
In 1978 the Royal Commission on the NHS stated that "where the tradition of using [accident and emergency departments for primary care] is strong, it may be preferable for the hospital to accept this role and make specific arrangements for fulfilling it, rather than to try and resist established local preferences." 2 Dale et al suggested that this hypothesis had been validated by their study. ${ }^{1}$ However, for the theory to be valid, it has to be shown not only that it is true in the inner city setting in which it is expected to be true, but that it should be false in a setting where the population is presumed to make more appropriate use of an A\&E unit.

Various studies seem to show a more "appropriate" consumption of resources by users of other units that were not in cities: $27 \%$ of patients attending a Stockholm hospital were of a "minor or non-acute nature," 3 and a study from Sheffield based on "processes of care" estimated that $23 \%$ of attendance episodes were unnecessary. ${ }^{4} \mathrm{~A}$ small pilot study in Eastbourne showed that if the criteria promulgated by King's were used, a substantial proportion of our workload would be classified as primary care work. In this prospective study we sought to determine the difference in the use of resources between inner London and Eastbourne if the same criteria of attendance were employed.

\section{Methods}

SETTING

Eastbourne District General Hospital is a large district hospital serving a population of about 185000 . The area may be described as semi-rural and no ward in the catchment area is considered deprived. There is an excess elderly indigenous population. The population rises by up to 50000 in the summer months with holidaymakers. The A\&E unit saw 38561 new patients in 1995-6, with a marked variation between summer and winter month attendances. The unit sees $30 \%$ more patients in summer than in winter. The study was designed to examine attendance patterns in two periods of 28 days in July to August and October to November 1995. Assessment was carried out only by experienced trained nursing staff ("E" grade or above, more than six months $A \& E$ practice), who had been familiarised with the criteria before the study began. No bank or temporary staff undertook assessment. Medical staffing of the unit is two consultants, one staff grade, and six senior house officers. 
The system of assessment used was identical to that described by Dale et al and used a reminder sheet for allocating patients after assessment. At the time, the unit was using a three category triage system, and a fourth category was added for those patients who could have seen the general practitioner, according to the Kings' College Hospital criteria.

\section{CRITERIA FOR CATEGORISATION}

Exactly as in the King's paper, it was considered that patients could have been seen in the primary care setting if they were self referred and not likely to require resuscitation, urgent care, or hospital admission. Patients with non-urgent complications of chronic conditions were also placed in this category.

Attenders were categorised as $A \& E$ patients if they were referred by the general practitioner, in need of urgent resuscitation, likely to require hospital admission, or had trauma requiring urgent hospital assessment.

\section{DATA COLLECTION}

Background research had shown that there was a variation in the attendance patterns at Eastbourne. The workload in October is approximately one third lower than that in July, and the majority of the excess in summer months was made up of visitors on holiday. The study compared these cohorts with each other and with the published data from King's College Hospital. Every patient in two periods of 28 consecutive days who attended for the first time with a new episode was entered into the study. No patient was excluded, and computer attendance records were compared to the paper record to ensure complete capture. As the service is provided by a stable population of medical staff, with no primary care practitioners or nurse practitioners employed, no further stratification was required. As no data were collected on medical staff performance during this time, the study was entirely open to medical staff, although patients were not told that the study was in progress to avoid any bias in symptom reporting. No attempt was made to compare case mix.

The variables collected were the assessment category, the date and time of attendance, and the four criteria used to decide whether the patient should be regarded as a primary care patient. Subsequent care was unaffected by the category assigned.

\section{STATISTICAL ANALYSIS}

Data were analysed by the independent statistical advice service of the South East Institute of Public Health.

\section{Results}

We analysed a total of 6519 patient episodes over 56 days; $3643(55.9 \%)$ attended in the summer and $2876(44.1 \%)$ in the winter.

SUMMER

Thirty four patients $(0.93 \%)$ were assessed to category $1,448(12.3 \%)$ to category 2,1566
$(42.9 \%)$ to category 3, and $1595(43.8 \%)$ to category 4 (the primary care category).

\section{WINTER}

Fifty four patients $(1.88 \%)$ were assessed to category $1,420(14.6 \%)$ to category 2,1290 $(44.8 \%)$ to category 3 , and $1112(38.7 \%)$ to category 4 .

Dale's data showed that $40.9 \%$ of his patients (2314 of 5658) were classified as presenting with "primary care" problems. This proportion was not significantly different from our winter figures $(\mathrm{p}=0.48,99 \%$ confidence interval around mean of difference, 0.051 to $-0.007)$. However, the summer figures were significantly different $(p=0.02,-0.0018$ to -0.056).

\section{Discussion}

There is a popular perception that the quality of care in general practice is better away from the inner cities, and it has been assumed that the corollary of this would be that use of $A \& E$ units is less "inappropriate." Dale and his coworkers developed criteria that they commended as concise, comprehensive, and straightforward to apply. Using these criteria, there was no discernible difference in use of an $A \& E$ unit by an inner city population and the winter population in Eastbourne. In the summer, however, when the population is swelled by tourists, Eastbourne had a significantly greater use of $\mathrm{A} \& \mathrm{E}$ facilities than King's.

There are two possible explanations for this. It may be that use of $\mathrm{A} \& \mathrm{E}$ facilities does not vary as much as had been assumed. Lowy et al looked retrospectively at 16 hospitals and found that between $15.7 \%$ and $33.3 \%$ of attendances were "unnecessary." They did not specify the location of hospitals, but none approaches the percentages seen in this study and there was little variation between them. The other explanation is hinted at by Dale et al-they noted that the method showed poor sensitivity, although they comment that the differences between primary care attenders and $A \& E$ patients was often very subtle.

From the data presented here, it can be seen that Dale's classification does not show that inner city $A \& E$ departments have any cause to claim special treatment; if general practitioner facilities are required in King's College Hospital they should also be allowed for in other areas. This suggests that the system that Dale recommends is not a valid method of classifying whether a person should be seen in the primary care setting and should not be used.

\section{CONCLUSION}

The method of assessment devised by Dale et $a l$ is not suitable for widespread use.

1 Dale D, Green J, Reid F, Glucksmann E. Primary care in the accident and emergency department: I. Prospective identification of patients. BMJ 1995;311:423-6.

2 Department of Health and Social Security. Royal Commission on the National Health Service. London: HMSO, 1978

3 Hansagi H, Edhag O, Allebeck P. High consumers of health care in emergency units: how to improve their quality of care. Qual Assur Health Care 1991;3:51-62.

4 Lowy A, Kohler B, Nicholl J. Attendance at accident and emergency departments: unnecessary or inappropriate? Public Health Med 1994; 16:134-40. 